\title{
$O$ desafio de operacionalizar as ações de vigilância sanitária no âmbito da promoção da saúde e no locus saúde da família
}

\author{
Gisele O'Dwyer ${ }^{1}$ \\ Maria de Fátima Lobato Tavares² \\ Marismary Horst De Seta ${ }^{3}$
}

O'DWYER, G.; TAVARES, M.F.L.; DE SETA, M.H. The challenge of rendering sanitary surveillance actions operational in health promotion and in the family health locus. Interface - Comunic., Saúde, Educ., v.11, n.23, p.467-84, set/dez 2007.

This article proposes an articulation between the Family Health and the Sanitary Surveillance fields of action. It reflects on how essential concepts and guidelines from Brazilian public health system, such as integrality, social control and health promotion, can be integrated into the practice of health professionals. Family Health is both a strategy for taking on a new practice and a field leading to comprehensiveness and health promotion, in addition to being conducive to community participation. Health promotion guides a practice which can potentially transform the field of health. Sanitary Surveillance acknowledges its connection to health promotion and its ideological affinity to the principles contained in the Ottawa Letter. In view of the complex social environment in which professional and user meet and of the hurdles to more effective health practices, training and enabling human resources becomes a tool for transforming and enhancing public health.

KEY WORDS: Sanitary surveillance. Family Health Program. Health promotion. Health human resource training.

Este artigo propõe uma articulação dos campos de ação da Estratégia Saúde da Família e Vigilância Sanitária. Reflete sobre como conceitos e diretrizes essenciais para o Sistema único de Saúde (SUS), como integralidade, controle social e promoção da saúde, podem incorporar-se na prática dos profissionais de saúde. A Saúde da Família constitui uma estratégia de enfrentamento de uma nova prática, é um dos campos de realização da integralidade e da promoção da saúde e favorece o controle social. A promoção da saúde é norteadora de uma prática com potencial de transformação da arena da saúde. A Vigilância Sanitária reconhece sua interface com a promoção da saúde e aproxima-se, ideologicamente, dos princípios da Carta de Ottawa. Reconhecendo a complexidade do ambiente social onde acontece o encontro profissional/usuário e os obstáculos para práticas de saúde mais efetivas, em um ambiente desfavorável, a capacitação de recursos humanos é uma ferramenta de transformação da saúde pública.

PALAVRAS-CHAVE: Vigilância sanitária. Programa Saúde da Família. Promoção da saúde. Capacitação de recursos humanos em saúde.

\footnotetext{
${ }^{1}$ Médica; mestre em Saúde Coletiva; pesquisadora e docente, Departamento de Planejamento e Administração em Saúde, Escola Nacional de Saúde Pública Sergio Arouca, Fundação Oswaldo Cruz, Rio de Janeiro, RJ. <odwyer@ensp.fiocruz.br>

${ }^{2}$ Médica; doutora em Ciências da Saúde; pesquisadora e docente, Departamento de Planejamento e Administração em Saúde, Escola Nacional de Saúde Pública Sergio Arouca, Fundação Oswaldo Cruz, Rio de Janeiro, RJ. <flobato@ensp.fiocruz.br>

${ }^{3}$ Enfermeira; doutora em Saúde Coletiva; pesquisadora e docente, Departamento de Planejamento e Administração em Saúde, Escola Nacional de Saúde Pública Sergio Arouca, Fundação Oswaldo Cruz, Rio de Janeiro, RJ. <deseta@ensp.fiocruz.br>
}

${ }^{1}$ Escola Nacional de Saúde Pública Sergio Arouca,

Departamento de Planejamento e Administração em Saúde, $7^{\circ}$ andar, sala 728

Rua Leopoldo Bulhões, 1480

Manguinhos - Rio de Janeiro, RJ

21.041-210 


\section{Introdução}

Este artigo busca discutir os principais desafios para qualificar as ações de vigilância sanitária com base em uma aproximação da prática de saúde da família, tomando como ponto de partida a lógica da promoção da saúde. Nesse contexto, insere-se a reflexão crítica sobre a possibilidade de criação de um espaço de interlocução para a vigilância sanitária, na medida em que várias de suas ações, como intervenções sobre os riscos oriundos do ambiente e do trabalho e monitoramento da qualidade dos serviços oferecidos, serão mais efetivas mediante o aprimoramento do controle social, igualmente importante para a saúde da família.

Para um novo processo de trabalho, tem sido destacada a coresponsabilização da equipe de saúde e da população-alvo do cuidado, com vistas à construção social das demandas e necessidades em saúde, que se expressariam, entre outras, numa reorganização das práticas para superar as respostas essencialmente assistenciais, no sentido de ações de promoção da saúde, formalmente instituída a partir de Ottawa (Brasil, 2001a).

Nesse sentido, entende-se a promoção da saúde enquanto uma estratégia de articulação transversal, na qual se confere visibilidade aos fatores/ situações de risco, aos diferentes grupos sociais e às diferenças entre necessidades, territórios e culturas presentes no nosso país, objetivando estabelecer mecanismos para reduzir as situações de vulnerabilidade, incorporar a participação e o controle social na gestão das políticas públicas, e defender a eqüidade. Nessa compreensão de ampliação do escopo das intervenções em saúde, em que são considerados os problemas e as necessidades de saúde articulados a seus determinantes, pode-se afirmar que a promoção da saúde estreita sua relação com o campo das vigilâncias em saúde. Utiliza-se, aqui, "vigilâncias em saúde", no plural, por se reconhecer a existência das vigilâncias epidemiológica, ambiental, sanitária e em saúde do trabalhador, e que elas se configuram de forma diferenciada no Sus e têm modos de atuação diversos ${ }^{4}$.

A noção de produção social da saúde é função e finalidade essencial, sem a qual não se cogita um novo processo de trabalho, e depende de uma orientação política que privilegie a incorporação do social na análise do processo saúde-doença e dos valores que os profissionais assumem para reger sua prática. Com base em um núcleo de saber (o saber específico de cada profissão), o campo de prática de saúde se conformaria como espaço de limites imprecisos onde cada profissional buscaria apoio de outros profissionais para cumprir seu trabalho (Campos, 2000).

A Organização Mundial de Saúde - OMS (1997) indicou a estratégia da promoção da saúde como metodologia de escolha para o desenvolvimento de ações abrangentes capazes de estimular a mudança do estilo de vida e das condições ambientais, econômicas e sociais que determinam a saúde, possibilitando a mudança no modelo de atenção e sendo, por isso, designada como guia para alcançar a meta Saúde para Todos no Século 21 (SPT/ séc.21), que reafirma a meta SPT/2000 para o novo século.

Concomitantemente, a renovação conceitual da Saúde Pública coloca a questão das funções essenciais, entendidas como atuações de um segmento
${ }^{4}$ Alguns epidemiologistas, a partir da década de 1990, empreenderam esforços para disseminar o saber epidemiológico entre as instituições de saúde. As propostas da Vigilância à Saúde nasceram de uma necessidade de romper a dicotomia tradicional entre a vigilância e a assistência, ou seja, as ações de vigilância deveriam ser incorporadas em todas as unidades de atenção à saúde. 0 modelo da Vigilância da Saúde surgiu em um contexto que favorecia a incorporação da epidemiologia em serviços de saúde (Paim, 2003), e suas ações incluíam o fortalecimento da vigilância epidemiológica e sanitária, ações de vigilância nutricional dirigida a grupos de risco, vigilância na área de saúde do trabalhador e vigilância ambiental, sem perder de vista a própria assistência (Teixeira, 2002). De forma sistematizada, são três vertentes da chamada "vigilância da/à/em saúde". O eixo comum é a abertura para a epidemiologia, tanto no que diz respeito à análise dos problemas de saúde, quanto à implantação de novas práticas e modelos assistenciais. A primeira equivale à análise da situação de saúde, abrange doenças e agravos para além do tradicional na vigilância epidemiológica, as doenças transmissíveis. A segunda corresponde à integração institucional das vigilâncias epidemiológica e sanitária, e concretizou-se mediante a criação de estruturas de vigilância nas esferas subnacionais, na primeira metade da década de 1990. A terceira pretende ser um modelo de atenção alternativo, com redefinição das práticas sanitárias e incorporação de outros sujeitos, inclusive, a representação da população organizada (Teixeira et al., 1998). 
específico e funcional do sistema de saúde, sendo conformadas em relação direta com as ações de toda a sociedade - as práticas sociais - que abarcam o amplo campo de seus fatores biológicos e sociais condicionantes $e$ determinantes, $e$ de sua atenção específica (Organização Panamericana de Saúde - OPS, 2002).

A promoção da saúde é considerada, então, como uma das funções essenciais da saúde pública e, como estratégia articulada às demais políticas e tecnologias desenvolvidas no SUS, possibilita pensar e operacionalizar ações para responder às necessidades sociais em saúde, dirigidas aos sujeitos e à coletividade.

Nessa perspectiva, a promoção da saúde pode ser entendida: como nível de atenção com ações destinadas a fomentar (no sentido de melhorar, incrementar) a saúde dos não enfermos; como enfoque com visão holística do processo de saúde-doença e da forma de intervir no mesmo (mudança na forma de entender e atuar em saúde); como função essencial da saúde pública, visando ações na comunidade que contêm, com ativa participação cidadã, fortalecimento da intersetorialidade e empoderamento para facilitar uma cultura da saúde (Buss, 2005). Segundo o autor, o Programa Saúde da Família (PSF) é um programa voltado para a promoção da saúde, que tem como objeto de intervenção o conjunto da população (independente do seu estado de saúde) e como campo de práticas, ações abrangentes de promoção, prevenção, assistência e recuperação da saúde. O conceito de empoderamento ("empowerment") tem sido relevante nos últimos anos e, no campo da saúde pública, tem sido utilizado como estratégia de ganho de saúde. Autores como Bernstein et al., 1994, Wallerstein \& Bernstein, 1994, e Thursz, 1993 (todos apud Teixeira, 2000), definem o empoderamento como a capacidade de as pessoas conseguirem maior compreensão e controle sobre suas forças pessoais, sociais, econômicas e políticas, agindo para a melhoria de sua situação de vida.

No ideário da promoção da saúde, este conceito apresenta-se como recurso importante para sustentabilidade das ações de educação para a saúde, orientadas, tanto individualmente quanto de forma coletiva, nos grupos sociais e organizações, por meio de processos educativos participativos. Para tal, buscará articulação de saberes técnicos e populares e a mobilização de recursos institucionais e comunitários, públicos e privados, para o enfrentamento e resolução de problemas de saúde e seus determinantes (Buss, 2000).

Assim, a promoção da saúde é retomada como possibilidade de compreensão do papel dos determinantes sociais na saúde e no adoecimento, como, por exemplo, desemprego, fome, dificuldade de acesso à educação, habitação

${ }^{5}$ Abrasco, Cebes, Abes, Rede Unida e Ampasa.o sus pra valer: universal, humanizado e de qualidade. Manifesto do Fórum da Reforma Sanitária Brasileira. Rio de Janeiro, julho de 2006. Disponível em: <http://

www.abrasco.org.br./ publicacoes/arquivos/ 20070306142552.pdf. Acesso em: 03 jul. 2006. inadequada, entre outros, deslocando o foco tradicional dos modos de viver, de uma perspectiva fragmentária e individualizante, para colocá-la numa perspectiva de construção coletiva e no contexto da própria vida dos sujeitos e coletividades. De outro, promove a articulação de diferentes saberes, reconhecendo a diversidade de atores e relações de poder, avaliando as respostas dos serviços em relação às demandas de saúde.

No que diz respeito às políticas, existem movimentos de qualificação das práticas e de fortalecimento do controle social, vide Humaniza SuS (Brasil, 2003), cartilha do usuário (Brasil, 2006a) e controle social no SUS ${ }^{5}$. A humanização pressupõe capacitação de profissionais, controle social e uma preocupação operativa com a reorganização dos serviços e das práticas. É por 
meio do diálogo e da comunicação que a humanização torna-se possível e a solidariedade abre uma perspectiva de humanização. Nesse sentido, humanizar a assistência implica dar lugar tanto à palavra do usuário quanto à palavra dos profissionais de saúde, de forma que possam fazer parte de uma rede de diálogo, que pense as ações de saúde com base na dignidade ética da palavra, do respeito, do reconhecimento mútuo e da solidariedade (Betts, 2006).

Partindo desses pressupostos, surgem os seguintes questionamentos: a) quais os processos educativos implementados para capacitar os profissionais de saúde que realizam ações de vigilância sanitária e aqueles das equipes de saúde da família, para o exercício desta prática? b) é possível articular tais práticas com base no locus saúde da família, tendo como eixo orientador a promoção da saúde? c) como impactar de forma positiva a saúde no âmbito das famílias, tendo como eixos a integralidade, a co-responsabilização e o empoderamento dos sujeitos-alvo das ações?

Não se propõe, no entanto, uma resposta conclusiva aos questionamentos anteriormente elencados, e sim, num primeiro momento, realizar uma aproximação e reflexão crítica dessas questões mediante o estabelecimento de um diálogo com alguns autores e documentos oficiais.

O primeiro passo foi a escolha de documentos e literatura. Trabalhou-se com as seis cartas das Conferências Internacionais da Promoção da Saúde (OMS, 2005; Brasil, 2001a), enfatizando os campos de ação e os papéis de mediação, educação e defesa da causa da saúde, e o projeto Saúde das Américas (OPS, 2002), que traz a discussão da "nova" saúde pública, das funções essenciais e das práticas sociais. A seguir, foram analisados documentos do Ministério da Saúde (Brasil, 2006b, 2001a, 1993), destacando-se: a Estratégia Saúde da Família, o Pacto da Saúde e a Política Nacional de Promoção da Saúde, e o Sistema Nacional de Vigilância Sanitária, que norteiam a organização das práticas (promoção da saúde, saúde da família e vigilância sanitária). Como técnica complementar, analisaram-se publicações científicas (com destaque para Lucchese, 2006; Buss, 2005, 2000; Starfield, 2002; Freire, 1997) que são referências nas áreas que circunscrevem a temática.

Partindo-se desses procedimentos - escolha dos documentos e literatura agruparam-se elementos em função de sua significação, de modo a facilitar a análise do material.

Os agrupamentos expressaram-se na ordenação das seguintes categorias nucleares: a) saúde da família enquanto prática de saúde; b) o cenário da promoção da saúde no locus saúde da família; c) interseção da prática de vigilância sanitária com a prática de saúde da família - apresentadas a seguir.

\section{Saúde da Família enquanto prática de saúde}

A Estratégia Saúde da Família (ESF) apresenta-se como uma possibilidade de reestruturação da atenção primária, com base em um conjunto de ações conjugadas em sintonia com os princípios de territorialização, intersetorialidade, descentralização, co-responsabilização e priorização de grupos populacionais com maior risco de adoecer ou morrer (Brasil, 1993). Desde a $10^{\text {a }}$ Conferência Nacional de Saúde, em 1996, essa estratégia se formaliza como uma importante expressão da política nacional de saúde e é 
apontada como potencialmente capaz de transformar o modelo hegemônico curativo e reparador, para a concretização da diretriz do Sistema único de Saúde de integralidade da atenção.

A concepção de Atenção Primária à Saúde (ATS), baseada na conceituação de Starfield (2002), destaca que os serviços nesse nível de atenção requerem: estar orientados para a comunidade, conhecendo suas necessidades de saúde em função do contexto econômico e social em que vivem; centrar-se na família, para bem avaliar como responder às suas demandas; ter competência cultural, para reconhecer as diferentes necessidades dos grupos populacionais, entendendo suas representações dos processos saúde-doença. Essas proposições têm interfaces com a ESF, entendida como política para reorganização do sistema de saúde brasileiro.

Sendo assim, a reorganização da atenção básica permite um novo processo de trabalho, onde o vínculo profissional/paciente e a co-responsabilização da equipe e da população atendida são condições para se alcançar resolutividade $e$ humanização no atendimento. As ações em saúde demandadas nesse nível do cuidado são inúmeras e têm forte potencial de impacto no padrão de morbidade e de mortalidade da população. Pesquisa realizada pelo Ministério da Saúde, em parceria com a Universidade de São Paulo e Universidade de Nova York, demonstra que a cada $10 \%$ de aumento de cobertura do PSF, o índice de mortalidade infantil cai em 4,6\% . O Projeto de Expansão e Consolidação da

${ }^{6}$ Dados do site www.saúde.gov.br/ dab/atencaobasica, Acesso em: 02 jul. 07. Saúde da Família (PROESF), realizado entre 2004 e 2005, produziu uma série de artigos com resultados de avaliação. Destacamos o de Szwarcwald (2006) como o que melhor indicou o potencial de modificação de indicadores assistenciais.

Diante da expectativa acima apontada, espera-se, da atenção básica, um serviço de alta qualidade, resolutivo, que valorize a promoção e proteção da saúde e que faça parte de um sistema hierarquizado (Costa \& Carbone, 2004).

Para o enfrentamento da complexidade inerente à atenção à saúde em uma sociedade tão desigual, a equipe de saúde da família precisa de uma maior proximidade com a população, pouco perceptível nas unidades "tradicionais" de atenção básica, onde a organização é centrada no modelo biomédico de assistência.

A equipe de saúde da família estaria, portanto, preparada para operacionalizar o conceito de integralidade da assistência. Uma integralidade referida às práticas de saúde e que responda para além das ações demandadas, geralmente assistenciais, e que, ao propor ações de proteção da saúde, seja capaz de fazê-lo de forma oportuna, na direção da prevenção de riscos futuros. Integralidade em conseqüência, como apreensão ampliada das necessidades do sujeito; uma capacidade de contextualizar adequadamente as ofertas a serem feitas àquele sujeito, de modo a identificar os momentos propícios a tal oferta. Isso significa ter habilidade de reconhecer a necessidade de adequação da oferta do cuidado ao contexto específico da situação no qual se dá o encontro do sujeito com a equipe de saúde (Mattos, 2004).

Para dar conta desse novo papel a ser exercido pela equipe de saúde, essa equipe precisa transformar sua prática na educação para a saúde, que não pode mais ser autoritária e normativa no enfrentamento de problemas, para os quais as intervenções em educação têm limites e possibilidades. O desafio é 
propor intervenções culturalmente sensíveis e adaptadas ao contexto no qual vivem as populações. Para cumprir tal desafio, as práticas de saúde devem ser entendidas como realidades socioculturalmente constituídas (Trad \& Bastos, 1998), e as técnicas de educação em saúde devem ser emancipatórias e ter no diálogo seu instrumento essencial (Alves, 2005). É inegável que a prática educativa em saúde também se coloca como instância capaz de multiplicar as ações dos serviços de saúde - na prevenção de doenças elou na promoção da saúde - e, como tal, fica subordinada aos objetivos imediatos e mediatos dos serviços, bem como à sua estruturação.

Os limites e possibilidades das intervenções em educação, citadas acima, precisam ser pensados à luz da dinâmica social e das mudanças do mundo do trabalho colocadas pela modernização. Essa impõe flexibilização produtiva, novas formas de organização do trabalho, acirramento da competição, revolução tecnológica e demanda um novo sujeito do conhecimento, com mais autonomia e em constante processo de aprendizagem. Impõe-se ao trabalhador a articulação dos diferentes saberes específicos com as dimensões éticopolíticas, comunicacionais e de inter-relações pessoais, que integram as subjetividades do relacionamento mútuo e o compartilhamento de idéias, boa parte desses saberes construídos no próprio ambiente de trabalho (Carvalho, 2004; Deluiz, 2001).

As mudanças no mundo do trabalho vêm colocando, aos profissionais de saúde, necessidades de desenvolvimento de competências que vão além de diagnosticar, prevenir, planificar, interferir, propor soluções, regular, gerir, negociar e avaliar em saúde. São exigidas, também, habilidades de negociação, de trabalhar cooperativamente, de compartilhar decisões. Particularmente na formação em saúde, essas exigências implicam a articulação de vários saberes: no conhecimento cientifico, no conhecimento técnico, na formação profissional e nas qualidades tácitas, nas experiências de trabalho e na vida social; no fomento ao estabelecimento de múltiplas relações entre pares - pessoal de serviço e da comunidade - que estimule os processos de colaboração e de troca, bem como, no desenvolvimento de processos significativos que integrem, além do saber fazer, a revisão dos modos de pensar (Tavares, 1998; Offe, 1991). Essa postura exige processo educacional prévio do profissional de saúde, que desenvolva a sua criatividade para acolher as necessidades do paciente. Freire (1997) e Bell et al. (2003) ressaltam que educar é respeitar a autonomia do educando, é ter consciência do "inacabamento" do ser humano, e criar possibilidade de diálogo, ao mesmo tempo, reconhecendo que a educação é ideológica. Essa reflexão sobre a capacitação do profissional no cenário globalizado atual é motivo de preocupação em função das demandas de atuação, particularmente para os profissionais de saúde da família, que sofrem os efeitos da formação profissional inadequada e que têm pouca formação na área de saúde pública (Gil, 2005).

A reorientação de serviços, objetivo da ESF, constitui um dos cinco campos de ação da promoção da saúde, que (re)coloca a incorporação dos determinantes do processo saúde/doença tanto no ensino dos profissionais de saúde quanto no exercício de sua prática, e aponta para o isolamento do conceito mecanicista de saúde ainda predominante no modelo assistencial atual (Tavares, 1990). Trata-se de superar uma prática ainda referenciada ao 
modelo de assistência hospitalocêntrico, centrado no indivíduo e na ação médica curativa, para buscar, no cotidiano dos serviços, um olhar mais abrangente e coerente com a promoção da saúde, que atinja os sujeitos e a coletividade, superando o foco sobre a doença no indivíduo.

Preocupado com a forma como as pessoas são atendidas na atenção básica, privilegiando seu núcleo de saber para atuar apenas sobre a doença, Cunha (2005) propôs a aplicação da clínica ampliada na atenção básica. Pretendia-se uma transformação na forma de atender o indivíduo e a coletividade, ampliando a oferta de ferramentas de cura, para além da medicina tradicional, e compreendendo as expectativas únicas de cada paciente, tornando a abordagem terapêutica menos normativa e construída coletivamente entre profissionais e indivíduos.

Por fim, a atenção básica é o local de resolução da maior parte dos problemas de saúde, e o local legítimo de realização da integralidade e do controle social, que mais que atributos são valores do Sus. O desafio é operacionalizar a atenção básica, dita primária por alguns autores e pensada como fundamental (plagiando a educação) pelas autoras.

\section{O cenário da promoção da saúde no locus saúde da família}

A promoção da saúde, definida como o processo que capacita a população a exercer o controle sobre a sua saúde, sendo, dessa forma, relativa ao bem-estar individual e coletivo (OMS, 2005, 1986), tem sido objeto de debate e produção científica. A carta de Ottawa (OMS, 1986) propõe cinco campos de ação para a promoção da saúde: ambientes favoráveis à saúde; construção de políticas públicas saudáveis; fortalecimento da ação comunitária; desenvolvimento de habilidades pessoais, enfatizando a divulgação de informação sobre saúde; reorientação dos serviços de saúde.

Como, para o SUS, a integralidade, a descentralização e o controle social são eixos norteadores, sua rede de prestação de serviços deve ser valorizada visando consolidar-se como espaço privilegiado de sociabilidade e politização de usuários, trabalhadores e gestores, espaços que contribuam para o aumento da capacidade reflexiva e de intervenção de diferentes sujeitos sobre o social (Carvalho, 2004).

Essa convergência entre os campos de ação preconizados na Carta de Otawa, reafirmada pela carta de Bangkoc (OMS, 2005), e os eixos norteadores do sus, do ponto de vista conceitual, tem sido amadurecida ao longo dos últimos vinte anos. O desafio que se impõe é transformar essas premissas em ações práticas, considerando a complexidade do ambiente social e cultural em que as ações de saúde acontecem. Outro aspecto do mesmo desafio é articular os fatores determinantes e/ou condicionantes que se imbricam na gênese ou manutenção dos problemas de saúde/doença e transcender o enfoque biologicista predominante no cotidiano das práticas.

Conforma-se assim, em linhas gerais, a problemática saúde/doença a exigir serviços de atenção primária, que até o presente - no caso de nosso país - são insuficientes em relação às necessidades básicas, ligadas à configuração da pobreza que determina as diversas formas de viver, adoecer e morrer da maioria da população. Necessidades cujas respostas nem sempre podem ser 
encontradas no setor saúde, motivo pelo qual requerem a conjugação de ações intersetoriais (Tavares, 1998).

O objetivo é superar os procedimentos que impedem, na prática, a visualização de como o social e o biológico interferem no processo de saúdel doença. Isto é, conceber e incorporar o social como dimensão importante desse processo e percebê-lo no plano da realidade histórica, socialmente construída, identificando-o no indivíduo. Para avançar, portanto, na direção da proposta de reorientação dos serviços, as ações para a promoção da saúde em APS devem ser constituídas pelo conjunto de atividades dos vários trabalhadores formalmente habilitados para realizá-las, sob a forma de "atenção/cuidados institucionalizados" (aspas do autor), e destinam-se à atenção integral às necessidades básicas de saúde, com ações também nos determinantes e a conseqüente busca da intersetorialidade (Tavares, 1998).

Conforme analisado, o contexto da prática em saúde lida com vários saberes. Um saber oriundo da ciência, que está muito mais relacionado ao conceito de doença do que ao de saúde, e um saber oriundo da experiência subjetiva de doença e saúde do indivíduo e da população. Partindo do pressuposto de que a formação dos profissionais de saúde está pautada no conhecimento da doença, quais os esforços necessários para viabilizar uma abordagem que leve em conta a saúde? Existem possíveis respostas para essas questões: investimento na formação continuada/permanente desses profissionais, enquanto metodologia de apreensão dos saberes provenientes da prática; no fortalecimento dos níveis locais de saúde; e na constituição de sujeitos sociais comprometidos com a operacionalização do conceito ampliado de saúde. Porque não basta a existência de um saber e o reconhecimento de uma necessidade em saúde para se enfrentar um contexto de prática tão complexo. É necessário um profissional com valores (éticos e políticos) e competências para apreender conhecimentos além do seu núcleo de saberes, que supere dicotomias entre práticas coletivas $e$ individuais, e capaz de reconhecer, investir e atuar sobre os recursos sociais existentes. Finalmente, com base no reconhecimento do desafio a ser enfrentado, um profissional apto a investir na parceria com a população e com os demais profissionais de saúde, incluindo os de vigilância sanitária.

A qualificação da prática dos profissionais de saúde, portanto, é a principal ferramenta que possibilitará a mudança na abordagem do paciente, da família $e$ da comunidade e a reorientação da atenção, sobretudo porque são os profissionais que executam as ações de educação em saúde, importantes para os objetivos da ESF, para a promoção da saúde e para a vigilância sanitária, como veremos melhor a seguir.

Por todo o analisado, entende-se que há convergência nas propostas da estratégia saúde da família e da promoção da saúde, colocando-se a primeira como lugar privilegiado para ações de intervenção nos determinantes da saúde, conforme preconizado pela segunda. Espera-se que o grupo de profissionais envolvidos no seu desenvolvimento esteja mais apto a enfrentar, nesse contexto complexo, os desafios sanitários contemporâneos. O campo da epidemiologia social reflete sobre essa complexidade ao trazer o foco de atenção, antes voltado sobretudo para os fatores de risco para a saúde, para examinar, com mais profundidade, o contexto social em que eles ocorrem (Carvalho, 2004).

Estudos (Valla et al., 2004; Valla, 2000) destacam a importância das 
estratégias de apoio social na manutenção da saúde, na prevenção das doenças e como forma de facilitar a convalescença, inserindo-se a educação para a saúde como prática necessária para estabelecer condições de desenvolvimento humano fundamentados nos valores de eqüidade, sustentabilidade $e$ democracia dirigidos aos determinantes da saúde, tal como contido nos pressupostos da promoção da saúde (Tavares, 2004).

Como vimos insistindo, a capacitação do profissional é uma ferramenta para a operacionalização da atenção básica. O treinamento de profissionais deve ser dialógico, crítico e reflexivo. Da mesma forma, deve ocorrer a comunicação entre profissionais e população. É possível introduzir, na prática cotidiana das equipes de PSF, as ações de promoção da saúde, estabelecer parcerias e articulações entre os diversos segmentos sociais, e operacionalizar os campos de ação da promoção da saúde. O diálogo crítico pode levar à emancipação dos sujeitos e assegurar saúde com qualidade de vida. Segundo Heidemann (2006), a incorporação das ações de promoção permanece ainda distante da prática concreta dos profissionais de saúde, porque é difícil incorporá-las no seu processo de trabalho, especialmente quando ainda prevalece um modelo de atenção à saúde que tem como base de sustentação o modelo biomédico.

\section{Qual a interseção da prática de vigilância sanitária com a prática da saúde da família?}

Resgatou-se, até aqui, a idéia de que a promoção da saúde é norteadora de uma nova prática, com potencialidade de transformação da arena da saúde. Fez-se a defesa de que a saúde da família é uma estratégia de construção de uma nova prática de saúde, capaz de contribuir na operacionalização das dimensões que o conceito ampliado de saúde coloca para a organização do cuidado de forma integral. Resta, portanto, reforçar a aproximação necessária para a vigilância sanitária dessa realidade, superando a pequena visibilidade social que a vigilância teve até o momento.

Conceitualmente, a Vigilância Sanitária é um conjunto de estratégias

${ }^{7}$ Por meio de uma agência ou da administração direta, o controle sanitário nos países se dá desmembrado em: alimentos e medicamentos: medicamentos e alimentos isoladamente; no caso dos serviços de saúde, em alguns países, a regulação sanitária se apóia em mecanismos de mercado, tais como a acreditação. Nesse sentido, há carência de experiências internacionais que guardem coerência e que sirvam de referência para o modelo brasileiro de vigilância sanitária. institucionais, administrativas, programáticas e sociais, integradas $e$ orientadas por políticas públicas que se destinam à produção social de saúde, com base em serviços, ações integrais e práticas essenciais para a defesa e promoção da vida em seu ambiente. As ações de vigilância são desenvolvidas por meio do exercício de práticas gerenciais e sanitárias, pretensamente democráticas e participativas, sob a forma de trabalho em equipe, dirigidas às populações de territórios delimitados, pelos quais assumem responsabilidade. Para eliminar, diminuir ou prevenir riscos à saúde, um conjunto de ações deve ser articulado, incluindo a integração com as ações de atenção básica.

Fora do Brasil, os arranjos institucionais destinados ao exercício da função essencial de saúde pública de regulação e fiscalização variam de país para país ${ }^{7}$. No Brasil, tanto a esse arranjo quanto ao conjunto de práticas que ele abriga, designou-se como vigilância sanitária. Ela integra o SUS por determinação constitucional e deve intervir sobre os riscos à saúde da população, sejam eles decorrentes do meio ambiente ou do processo de produção, comercialização e consumo de bens, assim como da prestação de serviços de interesse sanitário. 
Ou seja, as ações de vigilância sanitária inserem-se no âmbito das relações sociais de produção e consumo, onde se origina a maior parte dos problemas de saúde sobre os quais é preciso interferir (Costa \& Rozenfeld, 2000).

A Vigilância Sanitária detém, historicamente, o poder de polícia administrativa no campo da saúde, sua face mais visível para a sociedade. Mediante esse poder, que lhe assegura capacidade de intervenção sobre os problemas sanitários, cabe a ela restringir direitos individuais em benefício do interesse público. Seus modos de atuação compreendem atividades autorizativas (registro de produtos, licenciamento e autorização de funcionamento de estabelecimentos), normativas, de educação em saúde $e$ de comunicação com a sociedade ${ }^{8}$. As atividades autorizativas e normativas Ihe conferem caráter de ação regulatória, de ação de Estado, e precisam ser exercidas por agentes públicos com investidura para a função' não são passíveis de serem assumidas no contexto atual pelas equipes de saúde da família.

Entretanto, sem as atividades educativas e de comunicação - que devem permear toda a atenção à saúde, mormente a atenção básica - a vigilância sanitária não alcança efetividade. De um lado, há um saber específico da mesma, quanto à qualidade e segurança sanitária de produtos e serviços, que precisa dialogar com os saberes da população e dos profissionais que atuam nas demais ações de saúde. Assim, ao lidar com produtos e serviços presentes no cotidiano dos indivíduos - e relacionados com suas necessidades básicas -, a vigilância sanitária constitui um privilegiado espaço de comunicação e promoção da saúde. De outro lado, na interação da vigilância sanitária com a sociedade, deve-se, também, considerar a sua participação na definição dos riscos com os quais se aceita conviver, reduzindo-se o caráter eminente e pretensamente técnico da atual forma de decisão regulatória de que os segmentos de caráter popular não participam nem influem.

A organização dos serviços municipais de vigilância sanitária é muito diversa nos municípios brasileiros. As equipes têm constituição diferenciada em relação ao nível de escolaridade do profissional (nível médio e superior) e em relação ao tipo de graduação. O Censo Nacional dos Trabalhadores de vigilância sanitária de 2004 mostrou que $80,4 \%$ dos municípios tinham trabalhadores de vigilância sanitária, sendo que em $23,7 \%$ havia apenas um trabalhador e, do total, apenas 32,5\% tinham nível superior de escolaridade. Em relação ao tipo de graduação, $18 \%$ eram veterinários, $13 \%$ administradores, $12 \%$ farmacêuticos, $8 \%$ enfermeiros, $6 \%$ odontólogos e $5 \%$ médicos. Com base na pesquisa, foram considerados desafios para recursos humanos em vigilância sanitária: formar os trabalhadores com escolaridade de ensino médio; ajustar o quadro de trabalhadores às necessidades $e$ atribuições dos serviços; formular e implantar programa de educação permanente; e criar mecanismos de fixação e de valorização dos trabalhadores (Reis et al., 2005).

As ações de vigilância sanitária realizadas nos municípios também diferem, abrangendo, nos serviços de saúde, de consultórios (ação típica municipal) até serviços de média e alta complexidade (ação geralmente da visa estadual). Entretanto, existe um nível de ação básico em vigilância

\author{
${ }^{8}$ Como comunicação \\ com a sociedade \\ entenda-se aquela que \\ pretende o \\ empoderamento da \\ população e melhoria da \\ sua qualidade de vida e \\ do seu padrão de \\ consumo, reforçando a \\ "consciência sanitária" e \\ a cidadania, ao mesmo \\ tempo em que se espera \\ a redução da exposição a \\ riscos desnecessários. \\ Portanto, ela incorpora e \\ transcende a chamada \\ comunicação do risco, \\ que integra $o$ \\ gerenciamento do risco \\ sanitário.
}

${ }_{9}^{9}$ Agentes públicos investidos na função são servidores públicos concursados, ou ocupantes de cargo comissionado, com designação. Sem isso as ações de fiscalização podem ser passíveis de se tornarem nulas. 
${ }^{10}$ Dentre essas, a Mostra Cultural Vigilância Sanitária e Cidadania (<http// uww.ccs.saude.gov.br/ visa>) e material didático educativo para conselheiros de saúde. sanitária que é realizado de forma mais regular e que tem grande potencial de diálogo junto ao PSF. Trata-se da vigilância sobre farmácias, comércios de alimentos (açougues e supermercados) e consultórios médicos e odontológicos (inclusive, os das unidades do PSF).

As iniciativas de educação e comunicação desenvolvidas no âmbito da vigilância sanitária ainda são pontuais ${ }^{10}$ e há um grande espaço, precariamente explorado, para a ação educativa no âmbito da vigilância sanitária, tanto no que se refere ao entendimento do risco à saúde, envolvido nos atos e nas situações cotidianas, quanto no que se relaciona com os direitos de cidadania (Lucchese, 2006).

Levando-se em conta a baixa demanda social por ações coletivas de promoção e proteção da saúde, e o espaço restrito e resguardado em que se constituiu a vigilância sanitária ao longo de sua história, um dos principais desafios é garantir que as ações educativas cheguem à população e que recursos de proteção à saúde sejam utilizados na prática de todos os profissionais de saúde. Uma forma legítima de buscar essa aproximação é por meio da parceria com as equipes de saúde da família, que são os agentes de saúde mais próximos da população.

Partindo das proposições da promoção da saúde, tem-se a vigilância sanitária enquanto co-responsável no desenvolvimento de ações promocionais, contribuindo para o reforço da consciência sanitária por intermédio da informação e comunicação, entre outros. Uma primeira questão seria: como proceder para comunicar-se com a sociedade no sentido de qualificar a ação da vigilância no enfrentamento dos riscos e aproximá-la das ações de promoção da saúde? Ou seja, como transformar em prática a comunicação com a sociedade? Para tal, mediante as práticas da ESF, serão pontuadas as oportunidades da vigilância sanitária de trabalhar, junto à comunidade, a informação e a comunicação de forma contextualizada, tão necessária para maior efetividade no controle dos riscos.

Uma oportunidade relevante para essa comunicação é o momento de cadastramento das famílias e mapeamento de recursos, realizado pelo agente comunitário, onde devem ser descritos os recursos físicos, ambientais, institucionais e sociais do espaço onde vive uma comunidade. Nesse momento pode ser incluído um mapeamento dos espaços institucionais onde as ações de vigilância sanitária se darão. Espera-se que a comunidade compartilhe da informação sobre os recursos do espaço onde ela vive, inclusive, informações sobre a qualidade dos serviços de saúde. Cabe à vigilância sanitária monitorar a qualidade dos serviços de saúde utilizados pela população, sendo sua atuação fundamental no diagnóstico dos problemas dos serviços e proposição de soluções. O entendimento dos usuários sobre a importância de utilizar serviços de boa qualidade aponta para a possibilidade de avanços no exercício da cidadania, conquistados com base na orientação conjunta da vigilância e outros profissionais de saúde.

A constituição dessa parceria possibilita, aos profissionais da vigilância sanitária, a oportunidade de estarem em contato permanente com a população por meio das visitas domiciliares mensais e reuniões propostas pela equipe de PSF, que tem uma prática que extrapola os muros dos serviços e propicia um novo espaço de interlocução para a vigilância. 
A equipe de saúde da família pode ser o elo entre a comunidade e a equipe de vigilância sanitária. O agente comunitário é o primeiro profissional com o qual a comunidade se identifica. Deve ter liderança junto à comunidade $e$ percepção do contexto social e geográfico onde a comunidade está inserida. É o primeiro profissional a identificar situações de risco, norteadoras para a epidemiologia e para a prevenção, assim como para a vigilância sanitária. Algumas situações de risco, como descontinuidade de tratamento, abandono de idosos, negligência com crianças, alcoolismo, migração excessiva, desemprego e outras, são cotidianamente identificadas por esses profissionais e abordadas por toda a equipe de saúde da família. Dessa forma, é necessário incorporar, ao seu olhar, situações de risco ou agravo de importância para a vigilância sanitária, tais como: intoxicação alimentar, contaminação do ambiente, riscos trabalhistas, uso inadequado de medicamentos, entre outros.

Ao compartilharem com a população a vigilância sobre os riscos, os profissionais de vigilância sanitária e PSF fortalecem o empoderamento da população e propiciam o controle social. O aprimoramento do controle social, questão central para a saúde da família, também é contemplado como fundamental dentro da vigilância sanitária, como se constata, por exemplo, no esforço de constituição de ouvidorias, no intuito de abrir canais de comunicação com o usuário para o encaminhamento de reclamações, denúncias, sugestões e elogios. Desde a $1^{\text {a }}$ Conferência Nacional de Vigilância Sanitária - Efetivar o Sistema Nacional de Vigilância Sanitária: proteger e promover a saúde, construindo cidadania (Brasil, 2001b, 2001c) - questões como controle social, responsabilidade pública, democratização da informação, ética e cidadania estão na agenda de discussão da vigilância sanitária.

Uma primeira questão que se coloca para o diálogo entre a saúde da família $e$ a vigilância sanitária diz respeito ao conceito de território. Tradicionalmente, a vigilância sanitária trabalha com ele como divisão político-administrativa, ou seja, jurisdição. De um lado, isso é necessário pelo componente fiscal de sua ação. Assim, as ações de vigilância são circunscritas ao ente federativo responsável por aquela ação, para que elas tenham validade jurídica. Nesse sentido, é possível a ocorrência simultânea de ações das três esferas de governo numa mesma localidade. Para o PSF, a delimitação da área de abrangência das equipes, com vistas à adscrição de clientela, é geográfica, mas em geral, é realizada com base apenas no quantitativo de população, sem considerar a dinâmica social e política, inerente aos territórios (Pereira E Barcellos, 2006).

Porém, o conceito de território, procedente da Geografia, é mais compatível com as práticas de saúde coletiva, onde o território é o espaço vivido pelos homens (Santos, 2003), sendo também o teatro da ação de todas as empresas, de todas as instituições. Assim, o conceito de espaço geográfico representa uma categoria de síntese e de convergência de onde se expressam os diversos processos envolvidos nas condições de vida, ambiente e saúde das populações (Barcellos et al., 2002), e que tem grande potencial explicativo e de identificação de problemas (Monken \& Barcellos, 2005). Esse conceito de espaço geográfico, de território-processo, que não é incompatível com o de jurisdição, tem sido mais tematizado para a saúde da família, visto que se articula com as propostas de mudança do modelo assistencial.

$\mathrm{O}$ entendimento de território por parte dos técnicos e usuários do sistema 
de saúde tende a influenciar a forma como esse território será incorporado à prática de suas ações. Na sua concepção, o PSF busca visualizar o território na direção de uma perspectiva multiterritorial. Porém, a operacionalização dessa idéia enfrenta tendências reducionistas, fazendo com que os gestores locais, os agentes comunitários e a equipe como um todo, tenham concepções divergentes sobre o território (Pereira \& Barcellos, 2006).

Outra questão que se coloca é a do financiamento, no contexto das mudanças introduzidas com o Pacto 2006. No ano de 2006 foi aprovado o Pacto pela Saúde (Brasil, 2006b), resultado de um intenso trabalho de discussão envolvendo técnicos e a direção das diversas áreas do Ministério da Saúde, do Conselho Nacional de Secretários Municipais de Saúde (CONASEMS) e do Conselho Nacional de Secretários de Saúde (CONASS). Este pacto retoma questões referentes à descentralização, integralidade e controle social, além do financiamento. Os avanços identificados que podem contribuir com a discussão aqui travada dizem respeito ao fortalecimento do PSF e à forma de definir regiões de saúde para garantir oferta de serviços de baixa e média complexidade. Infelizmente, não houve avanço em questões referentes ao financiamento da vigilância sanitária.

Anteriormente, o Piso de Atenção Básica (PAB), dentre outras ações, continha o financiamento da saúde da família e da vigilância sanitária de caráter tipicamente municipal - as ações básicas. Com o Pacto, são constituídos cinco blocos de financiamento, um deles destinado à Atenção Básica e outro à Vigilância em Saúde. O primeiro, regulamentado pela Portaria $n^{\circ} 204$, de 2007, objetiva financiar a saúde da família (excetuando a assistência farmacêutica por ela realizada, que será custeada com recursos do bloco Assistência Farmacêutica) (Brasil, 2007). O bloco da vigilância em saúde é constituído dos recursos anteriormente destinados à vigilância epidemiológica e ambiental e à vigilância sanitária, podendo esses recursos transitar de um componente a outro, com possibilidade de se fragilizar o processo de construção desses serviços no nível municipal.

No que diz respeito ao Pacto da Atenção Básica, é reconhecido que o PSF,

${ }^{11}$ Segundo o

Ministério da Saúde, a ESF atingiu 5.106 municípios em 2006, com cobertura de $46,2 \%$ da população. Disponível em:

<www.saude.gov.br> Acesso em: 02 jul. 07. hoje, tem abrangência nacional ${ }^{11}$ e necessita de estruturação da sua rede de serviços. Os avanços a serem reconhecidos são, entre outros: a multidisciplinaridade, que ganha evidência com a inclusão do dentista na equipe; a valorização do processo de trabalho, incluindo o cuidado familiar ampliado, o monitoramento da assistência por meio de critérios de acompanhamento; a alimentação obrigatória dos sistemas de informação, possibilitando o diálogo entre entes federativos diversos; as estratégias de qualificação e capacitação das equipes com base em definições de atribuições, do processo de educação permanente e do investimento na graduação. O Pacto de Gestão define, de forma inequívoca, a responsabilidade sanitária de cada instância gestora do SUS: federal, estadual e municipal, superando o processo de habilitação anterior. Há uma ênfase na descentralização compartilhada, onde a integralidade das ações de saúde é garantida a partir da criação de Regiões de Saúde. Essas regiões são recortes territoriais inseridos em um espaço geográfico contínuo (não limitado ao município) que contemple uma rede de ações e serviços de saúde que propiciem um certo grau de resolutividade àquele território, com suficiência em atenção básica e parte da média complexidade. 
Ao município cabe a responsabilidade da atenção básica e das ações de vigilância em saúde. À região cabe a garantia do acesso às ações complementares em saúde. Portanto, politicamente, existe um cenário de nova responsabilidade sanitária, compartilhada entre gestores, com potencial de avançar na integralidade das ações ofertadas. Essa integralidade não é mais restrita à racionalização da oferta de serviços, concebida enquanto "integralidade da assistência à saúde", na perspectiva do cuidado médico, individual, curativo (Teixeira, 2002, p.155), já que há incorporação das ações de vigilância em saúde pelo município. O PSF, que no atual cenário é frágil na captação, formação e qualificação dos seus trabalhadores, é de responsabilidade do gestor municipal, que também deve garantir as ações de vigilância em saúde, estando aí incluídas ações básicas de vigilância sanitária. A gestão do risco sanitário, mesmo que perpasse as três esferas do governo em um mesmo território geográfico, tem, no nível local, entendido enquanto sistema municipal de saúde, o dever de exercer o controle social, que será fortalecido pela ação conjunta dos profissionais do PSF e vigilância sanitária.

Independente das regulamentações e formas de gestão, a vigilância sanitária deve ampliar seu objeto de ação e seu modo de trabalho. Para além de produtos e serviços, deve incluir, como objeto de ação, determinantes do processo saúde-doença e de qualidade de vida, e, para além da fiscalização, deve incluir, no seu trabalho, técnicas de comunicação (com a sociedade e com outros profissionais de saúde) e ações intersetoriais.

\section{Considerações finais}

Defendeu-se, até o momento, que a "nova" atenção básica (atenção fundamental na opinião das autoras) tem potencialidades para ser mais resolutiva, para aproximar-se da integralidade e propiciar humanização no atendimento; e que a vigilância sanitária é parceira no intuito de proteger e promover a saúde. Com essas colocações, desejou-se apostar na construção teórica do SUS e suas propostas, porém sem ignorar que a humanização da assistência acontece no dia-a-dia, na ponta (referindo-se a um jargão utilizado no nosso meio). Esse encontro, do usuário com o profissional e a equipe, qualifica-se com o investimento em processos educativos/formativos para o profissional e para o usuário, e com o mais efetivo controle social. A educação, proposta enquanto ferramenta, deve reconhecer sua ideologia emancipadora de uma nova relação. É o desafio apontado de investir em recursos humanos, transformando em prática a comunicação com a população e seu exercício de cidadania.

Como já apontado, operacionalizar o conceito de integralidade não é tarefa simples. É uma mudança, não só de estratégia ou de reorientação de modelo de atenção, mas de valor, onde o usuário não sinta que o sistema é excludente e o favorece ao ofertar serviços mais próximos de suas necessidades, e sim que ele tem direito a esses serviços. E que a equipe humanize seu trabalho ao negar o exercício do poder na sua relação com o usuário. Aí, sim, estaremos frente ao fortalecimento da ação comunitária e em um novo espaço de interlocução.

Para concluir, não podemos negar o grande avanço da ESF no Brasil, ao 
longo dos últimos anos, nem o esforço que a vigilância sanitária tem realizado no sentido de capacitar seus profissionais e descentralizar suas ações. No entanto, a cobertura da saúde da família ainda precisa de ampliação, assim como a estrutura de vigilância. Os processos de capacitação para os profissionais de saúde, apesar de merecer grande atenção e investimento por parte do Ministério da Saúde, ainda são incipientes em algumas regiões do país $e$ insuficientes para as necessidades apresentadas.

Muito ainda há a ser debatido sobre a temática da prática de saúde no SUS, da educação em saúde, da capacitação profissional e do controle social. E, sobretudo, ainda há muito a ser feito. Entretanto, não abdicamos da idéia de que o momento é propício para a implementação de um SUS mais capaz de promover, proteger, assistir e recuperar a saúde da população.

\section{Colaboradores}

A autora Gisele O'Dwyer participou de todas as etapas do artigo. Maria de Fátima Lobato Tavares participou da discussão, revisão do texto e revisão bibliográfica e Marismary Horst De Seta participou da revisão do texto e revisão bibliográfica.

\section{Referências}

ALVES, V.S. Um modelo de educação em saúde para o Programa de Saúde da Família: pela integralidade da atenção e reorientação do modelo assistencial. Interface - Comunic, Saúde, Educ., v.9, n.16, p 39-52, 2005.

BARCELLOS, C.C.; SABROZA, P.C; PEITER, P.; ROJAS, L.I. Organização espacial, saúde e qualidade de vida: análise espacial e uso de indicadores na avaliação de situações de saúde. Inf. Epidemiol. SUS, v.11, n.3, p.129-38, 2002.

BELL, B.; GAVENTA, J.; PETERS, J.; FREIRE, P.; HORTON, M. O caminho se faz caminhando, conversas sobre educação e mudança social. Petrópolis: Vozes, 2003.

BERNSTEIN, E; WALLESTEIN, N; BRAITHWAITE, B; GUTIERREZ, L.; ZIMMERMAN, M. Empowerment forum: a dialogue between guest editorial board members. Health Educ. Q., v.21, n.3, p.281-94, 1994.

BETTS, J. Considerações sobre o que é humano e o que é humanizar. Portal Humaniza. Disponível em: <http:www.portalhumaniza.org.br/ph/texto.asp?id=37. Acesso em: 8 nov. 2006.

BRASIL. Ministério da Saúde. Portaria n. 204/GM, de 29 de janeiro de 2007. Regulamenta o financiamento e a transferência dos recursos federais para as ações e os serviços de saúde, na forma de blocos de financiamento, com o respectivo monitoramento e controle. Brasília, 2007.

Carta dos Direitos dos Usuários em Saúde. Brasília, 2006a.

Portaria n. 399/GM, de 22 de fevereiro de 2006. Diretrizes do Pacto pela Saúde - Consolidação do Sistema Único de Saúde. Brasília, 2006b.

Portaria n. 699/GM, de 30 de março de 2006. Política de Promoção da Saúde. Brasília, 2006c. 
O'DWYER, G.; TAVARES, M.F.L.; DE SETA, M.H.

Política Nacional de Humanização (PNH), vinculada à Secretaria de Atenção à Saúde - SAS/ Ministério da Saúde. Brasília, 2003.

Promoção da Saúde. Declaração de Alma-Ata (1978), Carta de Ottawa (1986), Declarações de Adelaide (1988), Sundsval (1991) de Santafé, de Bogotá (1992), de Jakarta (1997), do México (2000). Rede dos Megapaíses. Brasília: Ministério da Saúde/PNUD, 2001a.

Saúde da Família: uma estratégia para reorientação do modelo assistencial. Brasília, 1993.

BRASIL. Agência Nacional de Vigilância Sanitária. In: CONFERÊNCIA NACIONAL DE VIGILÂNCIA SANITÁRIA - Efetivar o Sistema Nacional de Vigilância Sanitária: proteger e promover a saúde, 1., 2001, Brasília. Relatório Final... Brasília, 2001b.

In: CONFERÊNCIA NACIONAL DE VIGILÂNCIA SANITÁRIA - Efetivar o Sistema Nacional de Vigilância Sanitária: proteger e promover a saúde, 1., 2001, Brasília. Cadernos de Textos... Brasília 2001c. BUSS, P.M. Promoção da Saúde no Brasil. In: SEMINÁRIO BRASILEIRO DE AVALIAÇÃO DA EFETIVIDADE DA PROMOÇÃO DA SAÚDE, 1., 2005, Rio de Janeiro. Conferência de Abertura... Rio de Janeiro, 2005. (mimeogr.)

Promoção da saúde e qualidade de vida. Ciênc. Saúde Colet., v.5 n.1, p.163-77, 2000.

CAMPOS, G.W.S. Saúde pública e saúde coletiva: campo e núcleo de saberes e práticas. Ciênc. Saúde

Colet., v. 5 n.2 p.219-30, 2000.

CARVALHO, S.R. Os múltiplos sentidos da categoria "empowerment" no projeto da Promoção à Saúde. Cad. Saúde Pública, v.20, n.4, p.1088-95, 2004.

COSTA, E.A.; ROZENFELD, S. Constituição da Vigilância Sanitária no Brasil. In: ROZENFELD, S. (Org.). Fundamentos da Vigilância Sanitária. Rio de Janeiro: Fiocruz, 2000. p.15-40.

COSTA, E.M.A.; CARBONE, M.H. Saúde da família: uma abordagem interdisciplinar. Rio de Janeiro: Rubio, 2004.

CUNHA, G.T. A construção da clínica ampliada na atenção básica. São Paulo: Hucitec, 2005.

DELUIZ, N. O modelo das competências profissionais no mundo do trabalho e na educação: implicações para o currículo. Bol. Téc. SENAC, v.27, n.3, p. 13-25, 2001.

FREIRE, P. Pedagogia da autonomia: saberes necessários à prática educativa. Rio de Janeiro: Paz e Terra, 1997.

GIL, C.R.R. Formação de recursos humanos em saúde da família: paradoxos e perspectivas. Cad. Saúde Pública, v.21 n.2, p.490-8, 2005.

HEIDEMANN, I.T.S.B. A promoção da saúde e a concepção dialógica de Freire: possibilidades de sua inserção e limites no processo de trabalho das equipes de saúde da família. 2006. Tese (Doutorado) - Escola de Enfermagem de Ribeirão Preto, Universidade de São Paulo, Ribeirão Preto.

LUCCHESE, G. A Vigilância Sanitária no Sistema Único de Saúde. In: DE SETA, M.H.; PEPE, V. L. E.; OLIVEIRA, G.O. (Orgs.). Gestão e Vigilância Sanitária: modos atuais do pensar e fazer. Rio de Janeiro: Fiocruz, 2006. p.33-48.

MATTOS, R.A. A integralidade na prática (ou sobre a prática da integralidade). Cad. Saúde Pública, v.20, n.5, p.1411-6, 2004

MONKEN, M.; BARCELLOS, C. Vigilância em saúde e território utilizado: possibilidades teóricas e metodológicas. Cad. Saúde Pública, v.21, n.3, p.898-906, 2005.

OFFE, C. Trabalho \& Sociedade: problemas estruturais e perspectivas para o futuro da sociedade do trabalho. Perspectivas. Rio de Janeiro: Tempo Universitária, 1991. v.2. 
ORGANIZAÇÃO MUNDIAL DE SAÚDE. OMS. Carta de Bangkok. Washington: OPS, 2005. 1997.

. Ação intersetorial para a saúde: um pilar para a saúde para todos no século XXI. Genebra: OMS,

Carta de Ottawa. Washington, OPS, 1986.

ORGANIZAÇÃO PANAMERICANA DE SAÚDE. OPS. La Salud Pública en las Américas: nuevos conceptos, análisis del desempeno y bases para la acción. Washington: OPS, 2002.

PAIM, J.S. Epidemiologia e planejamento; a recomposição das práticas epidemiológicas na gestão do SUS. Ciênc. Saúde Colet., v.8, n.2, p.557-67, 2003.

PEREIRA, M.P.B.; BARCELLOS, C. O território no programa de saúde da família. Hygeia, v.2, n.2, p.47-55, 2006.

REIS, L.G.C.; GONDIM, M.M.G.; LIMA, L.C.W. Censo Nacional dos Trabalhadores de VISA. 2005. Disponível em: <www.anvisa.gov.br/institucional/snvs>. Acesso em: 02 jul. 2007.

SANTOS, M. Saúde e ambiente no processo de desenvolvimento. Ciênc. Saúde Colet., v.8, n.1, p.309-14, 2003.

STARFIELD, B. Atenção primária: equilíbrio entre necessidades de saúde, serviços e tecnologia. Brasília: Unesco/Ministério da Saúde, 2002.

SZWARCWALD, C.L. Indicadores de atenção básica em quatro municípios do Estado do Rio de Janeiro, 2005: resultados de inquérito domiciliar de base populacional. Ciênc. Saúde Colet., v.11, n.3, p.643-55, 2006.

TAVARES, M.F.L. Práticas em saúde e ensino para competência. Rio de Janeiro, 2004. (mimeogr.)

Saúde da criança e formação no trabalho: a prática como e com saber. 1998. Tese (Doutorado) Escola Nacional de Saúde Pública, Fundação Oswaldo Cruz, Rio de Janeiro.

Construção social do saber pediátrico. 1990. Dissertação (Mestrado) - Instituto Fernandes Figueira, Fundação Oswaldo Cruz, Rio de Janeiro.

TEIXEIRA, C.F. Promoção e vigilância da saúde no contexto da regionalização da assistência à saúde no SUS. Cad. Saúde Pública, v.18, supl., p.153-62, 2002.

TEIXEIRA, C.F.; PAIM, J.S.; VILASBOAS, A.L. SUS, modelos assistenciais e vigilância da Saúde. Inf. Epidemiol. SUS, v.7, n.2, p.7-28, 1998.

TEIXEIRA, M.B. Empoderamento de idosos em grupos direcionados à Promoção da Saúde. 2000. Dissertação (Mestrado) - Escola Nacional de Saúde Pública, Fundação Oswaldo Cruz, Rio de Janeiro.

THURZS, D. The case of empowerment. The possibilities of empowerment. J. Int. Fed. Ageing, v.20, n.1, p.1-2, 1993.

TRAD, L.A.B.; BASTOS, A.C.S. O impacto sócio-cultural do Programa de Saúde da Família (PSF); uma proposta de avaliação. Cad. Saúde Pública, v.14, n.2, p.429-35, 1998.

VALLA, V.V. Redes sociais, poder e saúde à luz das classes populares numa conjuntura de crise. Interface Comunic, Saúde, Educ., v.4, n.7, p.37-56, 2000.

VALLA, V.V.; GUIMARÃES M.B.; LACERDA, A. Religiosidade, apoio social e cuidado integral à saúde: uma proposta de investigação voltada para as classes populares. In: PINHEIRO, R.; MATTOS, R. A. (Orgs.). Cuidado: as fronteiras da integralidade. Rio de Janeiro: Hucitec; Abrasco, 2004. p.103-18.

WALLERSTEIN, N.; BERNSTEIN, E. Introduction to community empowerment, participation, education and health. Health Educ. Q., v.21, n.2, p.141-70, 1994. 
O'DWYER, G.; TAVARES, M.F.L.; DE SETA, M.H.

O'DWYER, G.; TAVARES, M.F.L.; DE SETA, M.H. El desafio de tornar operantes las acciones de vigilância sanitaria en el ámbito de la promoción de la salud y en el locus salud de la familia. Interface - Comunic., Saúde, Educ., v.11, n.23, p.467-84, set/dez 2007.

Este artículo propone una conexión entre los campos de acción de la Estrategia Salud de la Familia y la Vigilancia Sanitaria. Reflexiona sobre el modo como conceptos y directrices esenciales para el Sistema único de Salud (SUS), tales como integridad, participación social y promoción de la salud, pueden incorporarse en la práctica de los profesionales de salud. La Salud de la Familia constituye una estrategia para afrontar una nueva práctica, es uno de los campos de realización de la integralidad y la promoción de la salud y favorece la participación social. La promoción de la salud sirve de guía para una práctica con potencial de transformación de su campo de acción. La Vigilancia Sanitaria reconoce su interfaz con la promoción de la salud y se aproxima ideológicamente a los principios de la Carta de Ottawa. Reconociendo la complejidad del ambiente social donde ocurre el encuentro profesional-usuario y los obstáculos ante prácticas de salud más efectivas en un ambiente desfavorable, la captación de los recursos humanos es una herramienta de transformación de la salud pública.

PALABRAS CLAVE: Vigilancia sanitaria. Programa Salud de la Familia. Promoción de la salud. Capacitación de recursos humanos en salud.

Recebido em 13/09/05. Aprovado em 30/08/07. 